\title{
Testes size, body size and male-male competition in acanthocephalan parasites
}

\author{
Robert Poulin ${ }^{1}$ and Serge Morand ${ }^{2}$ \\ ${ }^{1}$ Department of Zoology, University of Otago, P.O. Box 56, Dunedin, New Zealand \\ ${ }^{2}$ Centre de Biologie et d'Ecologie tropicale et méditerranéenne, Laboratoire de Biologie Animale (UMR 5555 CNRS), Université de Perpignan, \\ 66860 Perpignan, France
}

(Accepted 15 June 1999)

\begin{abstract}
In most invertebrate taxa, males are smaller than females and large male sizes are only favoured when male-male competition for access to females is intense. In addition, in species where sperm competition is important, relatively large investments in testis growth and ejaculate size will also be selected. The use of copulatory plugs by males of some taxa, however, can prevent sperm competition. We hypothesized that, across related species in which males use plugs, relative testis size would decrease with increases in the severity of male-male competition. We tested this prediction across 112 species of acanthocephalan parasites, worms that use copulatory plugs and in which male-male competition occurs. As a measure of the intensity of male-male competition in a given species, we used sexual size dimorphism. Male and female body volume covaried allometrically, suggesting that sexual size dimorphism in acanthocephalans is the product of sexual selection. Our main finding is that relative testis volume, corrected for male body volume, decreases significantly as male body volume relative to female volume increases, i.e. as the sexual size dimorphism becomes less female-biased. All our results remained unchanged after we controlled for potential phylogenetic effects. The relationship indicates that investment in testis growth beyond the minimum size required for efficient fertilization becomes increasingly less important in species where males appear to compete intensely for mating opportunities.
\end{abstract}

Key words: Acanthocephala, parasites, phylogeny, sexual size dimorphism, sperm competition

\section{INTRODUCTION}

Sexual size dimorphism is extremely common in animals. To a certain extent the dimorphism may be a result of ecological divergence between the sexes (Shine, 1989), but in general the differentiation of reproductive roles and the sexual selection that followed appear as the main causes of sexual dimorphism (Fairbairn, 1997). In many groups, selection has favoured larger body size in females than males because of a fecundity advantage (Ridley, 1983; Arak, 1988; Hedrick \& Temeles, 1989). For instance, in most invertebrate taxa, where female fecundity usually correlates strongly with body size, female-biased size dimorphism is almost universal (e.g. Wicklund \& Karlsson, 1988; Poulin, 1996; Morand \& Hugot, 1998). Male body size, in contrast, seems to be influenced primarily by sexual selection, i.e. by the intensity of male-male competition for access to females (Ghiselin, 1974; West Eberhard, 1983). There is much

*All correspondence to: Robert Poulin.

E-mail: robert.poulin@stonebow.otago.ac.nz empirical evidence from a wide range of taxa showing that, across related species, the size of males relative to females increases with increasing levels of male-male competition (Björklund, 1990; Mitani, Gros-Louis \& Richards, 1996; Poulin, 1997a). Sperm competition can also play a role in the evolution of male body size; ejaculate size is also driven by sexual selection, and it correlates positively with body size in most taxa (e.g. Harcourt et al., 1981; Møller, 1989, 1991; Wedell, 1997).

Male-male competition sensu stricto and sperm competition may lead to a trade-off between investments in testis growth and sperm production on the one hand, and somatic growth on the other hand. As the size of males relative to that of females increases among related species, the relative investment in testis growth, corrected for male body size, also increases (Møller, 1991; Wedell, 1997). In other words, intense sexual selection favours high investments in both somatic growth and testis growth. This should lead to a trade-off in which somatic and testis growth achieve an optimal compromise (Stearns, 1992). In taxa where sperm competition is very limited, however, we may expect that relative 
investments in testis growth will not increase and may even decrease as the sexual size dimorphism tilts in favour of males.

Acanthocephalan worms may be such a taxon. Adult acanthocephalans parasitize the intestines of vertebrates, where they mate. In most species, the sex ratio is femalebiased (Poulin, 1997b), and females are markedly larger than males (Crompton, 1970, 1985). Males and females aggregate in sexual congress (Richardson, Martens \& Nickol, 1997), during which a single male can inseminate several females while other males do not succeed in mating (Crompton, 1974, 1985). Body size seems to be important in obtaining access to females and determining reproductive success in males (Parshad \& Crompton, 1981). After mating, acanthocephalan males plug the female gonopore with a cement which they secrete (Crompton, 1970, 1985), preventing further inseminations in the near future and thus sperm competition. Exactly how efficient these plugs are is unknown, but they appear to work for at least some time after mating (Crompton, 1970, 1985). Males can also grab rival males and place a cement plug on their reproductive organs (Abele \& Gilchrist, 1977), preventing them at least temporarily from inseminating females. Acanthocephalans therefore show female-biased sex ratios, high variance in male reproductive success with larger males being more successful, and no or very weak sperm competition. These parasitic worms thus present all the conditions for decreases in relative testis size with increases in male-male competition, i.e. with increases in male size relative to females.

Here we test this prediction using comparative data and controlling for phylogenetic influences. We use the size of males relative to that of females as a measure of the intensity of sexual selection. Ideally, another, independent measure of sexual selection would have been desirable (see Cheverud, Dow \& Leutenegger, 1985); however, in other taxa sexual size dimorphism has proven a reliable predictor of male-male competition (Mitani et al., 1996; Poulin, 1997a) and it is the only comparative index available for several species. Observing the postulated negative relationship between sexual size dimorphism and relative investments in testis growth would suggest that in the absence of sperm competition, testis size is kept to the minimum necessary for efficient fertilization. We also examined whether absolute testis size increases proportionally with female body size, to determine if a larger ejaculate size is selected in species with large females, which should be more fecund than small females. Our study complements previous ones performed on taxa where sperm competition can be intense (Harcourt et al., 1981; Møller, 1988, 1989, 1991; Cook \& Wedell, 1996; Wedell, 1997).

\section{METHODS}

Data on adult female body size, adult male body size and testis size were obtained from the catalogue compiled by Petrochenko (1956, 1958) and from original descriptions of species published between 1960 and 1990 in either the Journal of Parasitology or the Proceedings of the Helminthological Society of Washington. Male and female acanthocephalans are roughly cylindrical in shape; therefore for each species, male volume and female volume were calculated as $\left(\pi l w^{2}\right) / 4$, where $l$ is average body length and $w$ is average body width. Testes are usually ovoid, and for each species the volume of each testis was estimated as $\left(\pi l w^{2}\right) / 6$, where $l$ is average testis length and $w$ is average testis width. Total testis volume was obtained as the sum of the volumes of the anterior and posterior testes, which usually differ slightly in size.

Sexual size dimorphism was first computed as the ratio of female volume to male volume, in order to obtain a distribution of relative dimorphism among species. For analytical purposes, however, we used the residuals of a linear regression of male volume on female volume as comparative measures of sexual size dimorphism for 2 reasons. First, this measure is preferable to the ratio of female and male volumes because it is not sensitive to the shape of the relationship between male and female volumes (Ranta, Laurila \& Elmberg, 1994). Second, the slope of the regression itself can suggest the action of sexual selection (Fairbairn \& Preziosi, 1994). A slope of 1 indicates that sexual dimorphism varies isometrically with body size, possibly because it is constrained. When females are larger than males, a slope that differs from 1 , particularly a hypoallometric relationship (slope <1) where female size increases at a faster rate than male size, i.e. sexual dimorphism increases with size, suggests the action of sexual selection (Fairbairn \& Preziosi, 1994). Other causal mechanisms can produce allometry, but most explanations postulate a role for sexual selection (Fairbairn, 1997).

Total testis volume correlates with male body volume. To obtain measures of testis volume corrected for male volume, i.e. measures of investment in testis growth relative to body size, the residuals of a regression of total testis volume on male volume were used. However, a second-order polynomial regression was used because it provided a much better fit to the data than a linear regression, and because it gave residuals that were normally distributed whereas those obtained from a linear regression were not. We tested whether the polynomial regression provided a better fit than a linear regression using the $F$-test proposed by Zar (1984: 365). The polynomial regression was chosen simply for these empirical and statistical reasons, and not as the representation of any underlying biological process. We also regressed total testis volume against female body volume to look for potential selection on ejaculate size mediated by female body size.

Analyses were performed both across log-transformed species values and across phylogenetically independent contrasts (Felsenstein, 1985; Harvey \& Pagel, 1991) to highlight the influence of phylogeny, if any, on the patterns observed. Contrasts were computed on logtransformed data using the CAIC 2.0 software package (Purvis \& Rambaut, 1994). A phylogeny was inferred 


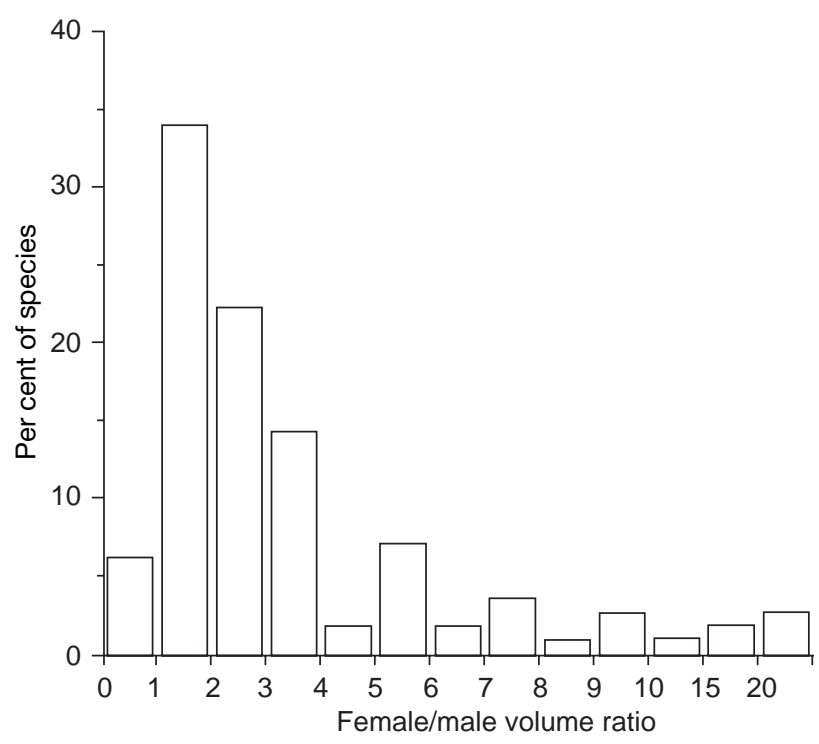

Fig. 1. Frequency distribution of sexual size dimorphism (ratio of female volume to male volume) across 112 species of acanthocephalan parasites.

from the acanthocephalan classification of Amin (1985, 1987), with additional information obtained from Golvan (1994). Data on branch lengths in the phylogeny are not available. We therefore assumed that branch lengths are equal (i.e. punctuated evolution model); this has proved the most robust option when true branch lengths are unknown in simulation studies (Purvis, Gittleman \& Luh, 1994). All regressions and correlations involving contrasts were forced through the origin (see Garland, Harvey \& Ives, 1992, for justification).

\section{RESULTS}

Data were obtained for 112 species, representing 47 genera (see Appendix). In all species, females are larger than males. In most species, females are no more than three times more voluminous than males, although the sexual size dimorphism can be much more pronounced in certain taxa (Fig. 1).

Analyses across species values gave results almost identical to those obtained using phylogenetically independent contrasts. Male volume correlated strongly with female volume (species values: $n=112, r^{2}=0.794$, $P=0.0001$; contrasts: $\left.n=41, r^{2}=0.834, P=0.0001\right)$. The relationship, however, was hypoallometric (Fig. 2), i.e. the slope of the regression was inferior to one (species values: slope $=0.767,95 \%$ confidence intervals $(\mathrm{CI})=0.694$ to 0.841 ; contrasts: slope $=0.703,95 \%$ $\mathrm{CI}=0.643$ to 0.763 ). In Fig. $2 \mathrm{~b}$ there is an obvious outlier in the top right-hand corner of the plot; it corresponds to a contrast computed at the basal node of the phylogeny, i.e. computed among classes of acanthocephalan. Removing this outlier increases the estimate of the slope (to 0.720) but it still differs from one.

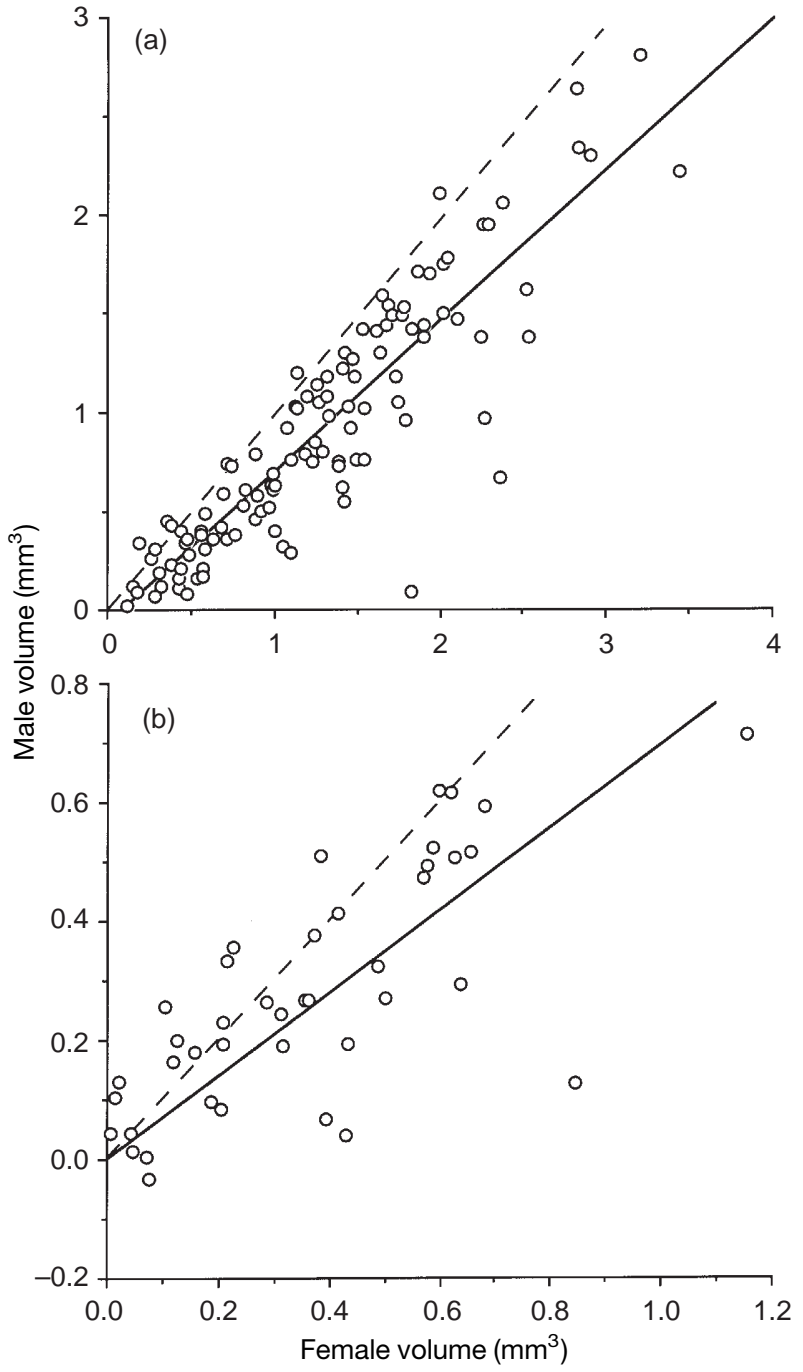

Fig. 2. Relationship between male body volume and female body volume in parasitic acanthocephalans: (a) species values $(y=0.767 x-0.064)$; (b) independent contrasts $(y=0.703 x)$. Broken lines represent an isometric relationship (slope $=1$ ). Data are $\log _{10}(x+1)$-transformed volumes.

Total testis volume and male body volume were also strongly correlated (Fig. 3). This relationship was not linear and was best explained by a polynomial function (species values: $n=112, r^{2}=0.640, P=0.0001$; contrasts: $n=41, r^{2}=0.669, P=0.0001$ ), in which testis volume increases at a much faster rate than male volume. The polynomial regression provided a statistically significantly better description of the relationship than a linear regression (species: $F_{1,109}=51.55, P<0.001$; contrasts: $\left.\mathrm{F}_{1,38}=17.51, P<0.001\right)$.

Using residuals from the above regressions as measures of male volume corrected for female volume (i.e. sexual size dimorphism), and testis volume corrected for male volume, we found a significant negative relationship between relative male size and relative investment in testis growth (Fig. 4). This negative relationship was observed both before and after controlling for potential phylogenetic effects (species values: $n=112, r=-0.242$, 


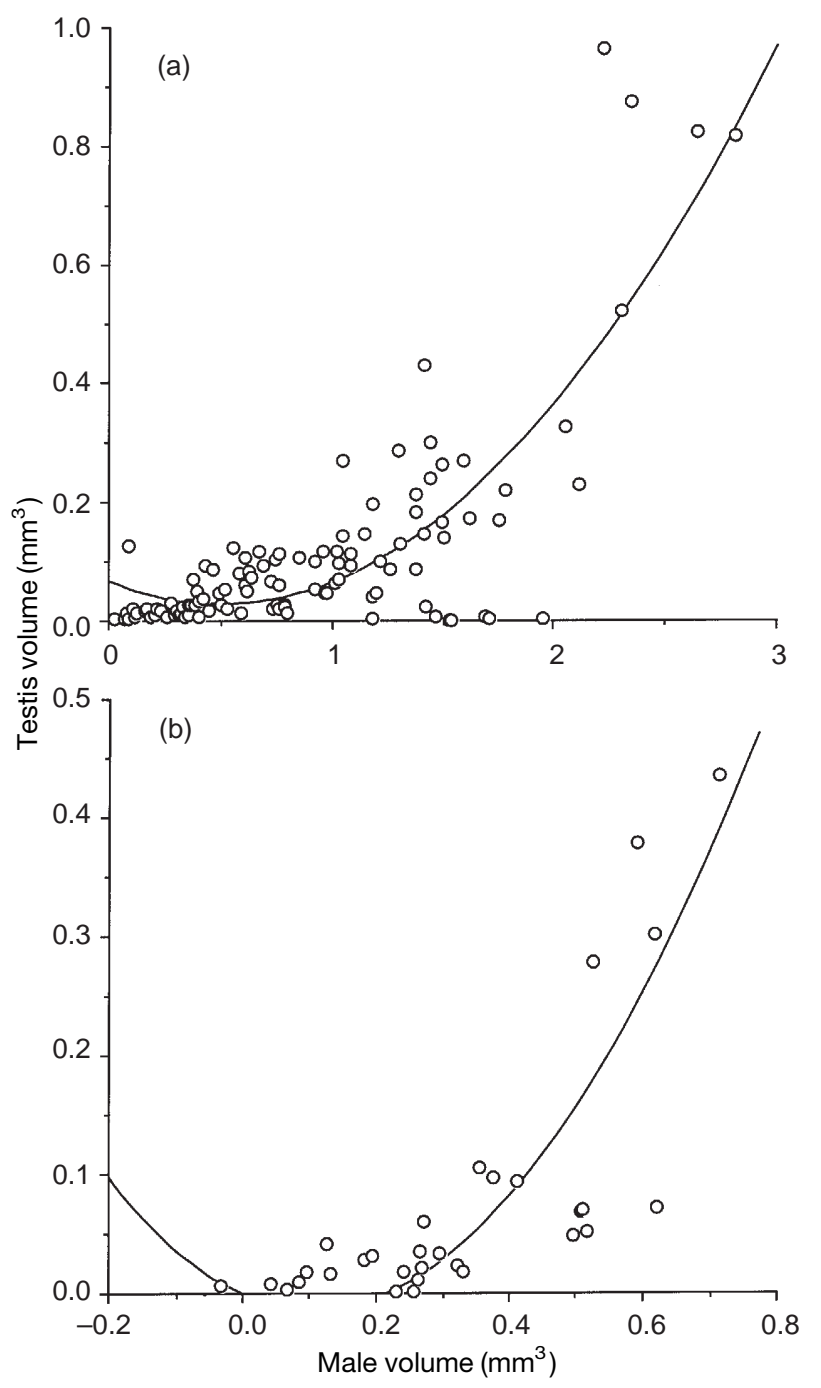

Fig. 3. Relationship between total testis volume and male body volume in parasitic acanthocephalans: (a) species values $\left(y=-0.154 x+0.152 x^{2}+0.067\right) ; \quad$ (b) independent contrasts $\left(y=-0.284 x+1.086 x^{2}\right)$. Data are $\log _{10}(x+1)$-transformed volumes.

$P=0.0086$; contrasts: $n=41, r=-0.312, P=0.047)$. In other words, as relative male body size approaches female body size, investment in testis growth decreases.

Total testis volume (absolute, not corrected for male volume) covaried linearly with female body volume (species values: $n=112, r^{2}=0.463, P=0.0001$; contrasts: $\left.n=41, \quad r^{2}=0.471, \quad P=0.0001\right) ; \quad$ polynomial functions did not provide a better fit to the data. The slopes, however, were clearly hypoallometric (species values: slope $=0.164$; contrasts: slope $=0.188$ ). This means that testis volume in males increases at a much slower rate than female body volume.

\section{DISCUSSION}

Producing copious amounts of sperm is a common strategy in animal species where males face intense

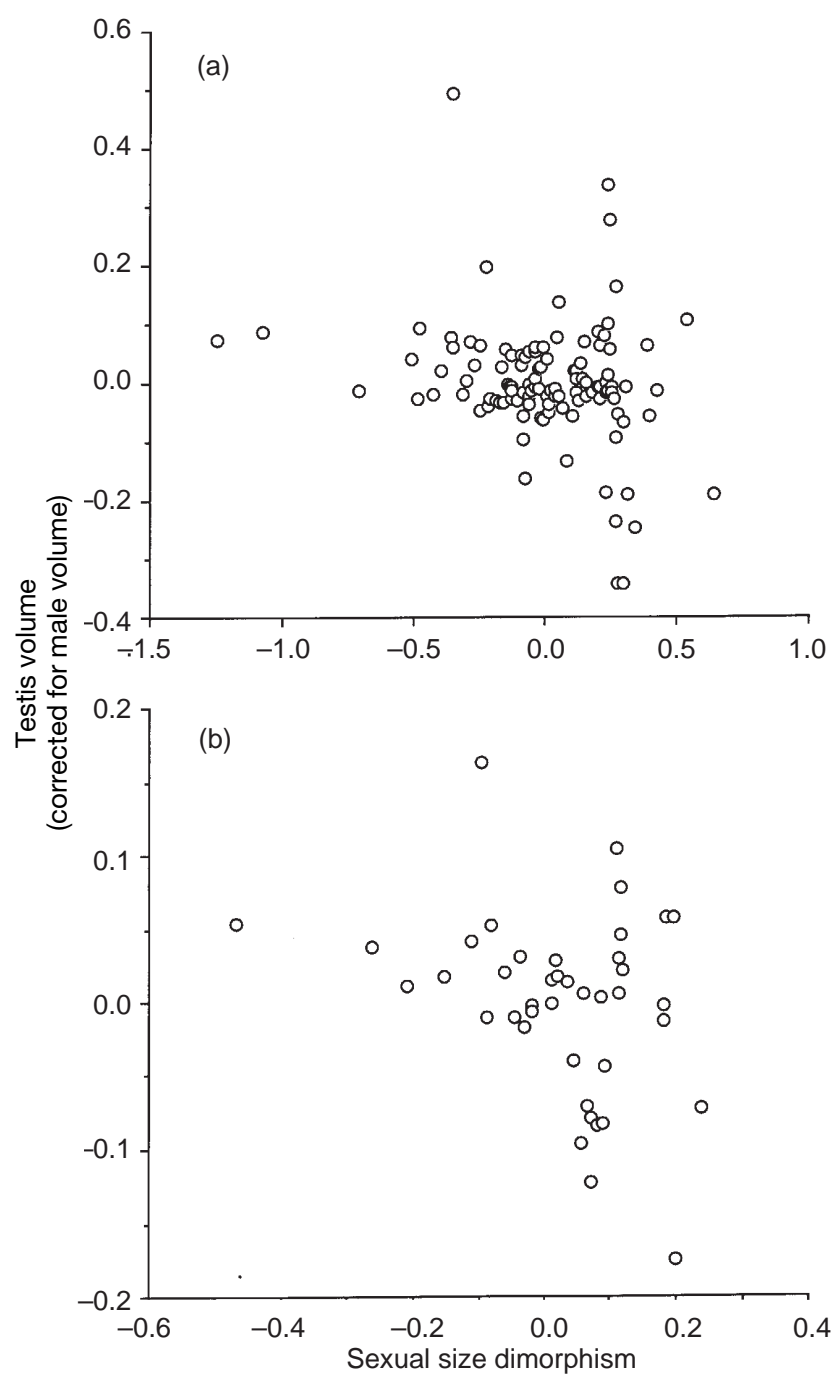

Fig. 4. Plot of relative testis volume (corrected for male body volume) against a measure of sexual size dimorphism, i.e. male body volume corrected for female body volume: (a) species values; (b) independent contrasts. Data are residuals from the regressions of Figs $2 \& 3$.

sperm competition (Harcourt et al., 1981; Møller, 1989, 1991; Cook \& Wedell, 1996; Wedell, 1997). In acanthocephalans, the use of copulatory plugs by males greatly reduces the likelihood of sperm competition (Crompton, 1970, 1985). The results of our comparative analysis show clearly that relative investment in testis growth decreases as the intensity of male-male competition for access to females, measured using sexual size dimorphism, increases. Obviously, sexual size dimorphism is not the ideal substitute for a more direct measure of the intensity of male-male competition; it has, however, often been shown to provide a reliable index of this competition (Mitani et al., 1996; Poulin, 1997a). However, the results still suggest that large ejaculate size is of little advantage to acanthocephalans, and that the relative value of large testes decreases with increasing male body size. The highly hypoallometric relationship between testis volume and female body 
volume also suggests that female body size itself does not select for large testis size in males.

We could only address the male side of the equation in our study. Female body size or female investment in reproduction may change in response to male-male competition and/or sperm competition. There were insufficient data on ovary size or other measures of female reproductive investment to investigate this possibility. Another research direction made difficult by the unavailability of data is using the sex ratio as a more direct measure of the intensity of sexual selection. Crompton $(1970,1985)$ points out, however, that the acanthocephalan sex ratio varies considerably over time because of the great difference in the longevity of males and females, perhaps making it a more variable estimate of the intensity of male-male competition. There exist some comparative data on acanthocephalan sex ratios (Poulin, 1997b), but unfortunately not on a sufficient number of the species included here to allow a meaningful analysis.

The relationship between male volume and female volume was hypoallometric, i.e. with a slope smaller than one. In groups where females are always larger than males, this means that sexual size dimorphism increases with increasing average body size, and tends to be more pronounced in large-bodied species than in small-bodied ones. Previous workers suggested that a hypoallometric relationship between male and female body size supports a role for sexual selection in the evolution of sexual size dimorphism, without excluding other mechanisms (Fairbairn \& Preziosi, 1994; Fairbairn, 1997). The information previously available on the reproductive biology of acanthocephalans (Crompton, 1970, 1974, 1985; Abele \& Gilchrist, 1977; Parshad \& Crompton, 1981; Richardson et al., 1997) strongly suggests that male-male competition plays an important role in these worms. Other components of sexual selection may somewhat weaken the link between male-male competition and sexual size dimorphism. For instance, there is circumstantial evidence that males may be choosy when mating with females, preferring larger females (Lawlor et al., 1990). Still, our results and most previous observations point toward an important role of sexual selection in the evolution of sexual size dimorphism in acanthocephalans, making this measure a good comparative index of the strength of sexual selection in a given species.

In summary, we find that in species where male-male competition appears intense, male acanthocephalans invest less in testis growth. Growth of testes beyond the minimum size required to ensure fertilization is not favoured in this taxon, where sperm competition is prevented or at least minimized by the use of copulatory plugs by males. Most comparative studies to date have focused on groups where sperm competition can be severe (Harcourt et al., 1981; Møller, 1989, 1991; Cook \& Wedell, 1996; Wedell, 1997). It will now be interesting to see if the patterns observed among acanthocephalans also occur in other invertebrate taxa where sperm competition is of limited importance.

\section{Acknowledgements}

We are grateful to Anne Ducreux for her help in compiling the data set. RP thanks the Universite de Perpignan for financial support during his visit.

\section{REFERENCES}

Abele, L. G. \& Gilchrist, S. (1977). Homosexual rape and sexual selection in acanthocephalan worms. Science 197: 81-83.

Amin, O. M. (1985). Classification. In Biology of the Acanthocephala: 27-72. Crompton, D. W. T \& Nickol, B. B. (Eds). Cambridge: Cambridge University Press.

Amin, O. M. (1987). Key to the families and subfamilies of Acanthocephala, with the erection of a new class (Polyacanthocephala) and a new order (Polyacanthorhynchida). J. Parasitol. 73: $1216-1219$.

Arak, A. (1988). Sexual dimorphism in body size: a model and a test. Evolution 43: 820-825.

Björklund, M. (1990). A phylogenetic interpretation of sexual dimorphism in body size and ornament in relation to mating system in birds. J. Evol. Biol. 3: 171-183.

Cheverud, J. M., Dow, M. \& Leutenegger, W. (1985). The quantitative assessment of phylogenetic constraints in comparative analyses: sexual dimorphism in body weight among primates. Evolution 39: 1335-1351.

Cook, P. A. \& Wedell, N. (1996). Ejaculate dynamics in butterflies: a strategy for maximizing fertilization success? Proc. $R$. Soc. London B Biol. Sci. 263: 1047-1051.

Crompton, D. W. T. (1970). An ecological approach to acanthocephalan physiology. Cambridge: Cambridge University Press.

Crompton, D. W. T. (1974). Experiments on insemination in Moniliformis dubius (Acanthocephala). Parasitology 68 : 229-238.

Crompton, D. W. T. (1985). Reproduction. In Biology of the Acanthocephala: 213-271. Crompton, D. W. T \& Nickol, B. B. (Eds). Cambridge: Cambridge University Press.

Fairbairn, D. J. (1997). Allometry for sexual size dimorphism: pattern and process in the coevolution of body size in males and females. Annu. Rev. Ecol. Syst. 28: 659-687.

Fairbairn, D. J. \& Preziosi, R. F. (1994). Sexual selection and the evolution of allometry for sexual size dimorphism in the water strider, Aquarius remigis. Am. Nat. 144: 101-118.

Felsenstein, J. (1985). Phylogenies and the comparative method. Am. Nat. 125: 1-15.

Garland, T., Harvey, P. H. \& Ives, A. R. (1992). Procedures for the analysis of comparative data using phylogenetically independent contrasts. Syst. Biol. 41: 18-32.

Ghiselin, M. T. (1974). The economy of nature and the evolution of sex. Berkeley, CA: University of California Press.

Golvan, Y. J. (1994). Nomenclature of the Acanthocephala. Res. Rev. Parasitol. 54: 135-205.

Harcourt, A. H., Harvey, P. H., Larson, S. G. \& Short, R. V. (1981). Testis weight, body weight and breeding system in primates. Nature (Lond.) 293: 55-57.

Harvey, P. H \& Pagel, M. D. (1991). The comparative method in evolutionary biology. Oxford: Oxford University Press.

Hedrick, A. V. \& Temeles, E. J. (1989). The evolution of sexual dimorphism in animals: hypotheses and tests. Trends Ecol. Evol. 4: 136-138.

Lawlor, B. J., Read, A. F., Keymer, A. E., Parveen, G. \& Crompton, D. W. T. (1990). Non-random mating in a parasitic worm: mate choice by males? Anim. Behav. 40: 870-876.

Mitani, J. C., Gros-Louis, J. \& Richards, A. F. (1996). Sexual dimorphism, the operational sex ratio, and the intensity of male competition in polygynous primates. Am. Nat. 147: 966-980. 
Møller, A. P. (1988). Ejaculate quality, testes size and sperm competition in primates. J. Hum. Evol. 17: 479-488.

Møller, A. P. (1989). Ejaculate quality, testis size and sperm production in mammals. Funct. Ecol. 3: 91-96.

Møller, A. P. (1991). Sperm competition, sperm deletion, paternal care, and relative testis size in birds. Am. Nat. 137: 882-906.

Morand, S. \& Hugot, J.-P. (1998). Sexual size dimorphism in parasitic oxyurid nematodes. Biol. J. Linn. Soc. 63: 397-410.

Parshad, V. R. \& Crompton, D. W. T. (1981). Aspects of acanthocephalan reproduction. Adv. Parasitol. 19: 73-138.

Petrochenko, V. I. (1956). Acanthocephala of domestic and wild animals, I. Moscow: Academy of Sciences of the USSR (English version: 1971, Israel Program for Scientific Translations, Keter Press, Jerusalem).

Petrochenko, V. I. (1958). Acanthocephala of domestic and wild animals, II. Moscow: Academy of Sciences of the USSR (English version: 1971, Israel Program for Scientific Translations, Keter Press, Jerusalem).

Poulin, R. (1996). Sexual size dimorphism and transition to parasitism in copepods. Evolution 50: 2520-2523.

Poulin, R. (1997a). Covariation of sexual size dimorphism and adult sex ratio in parasitic nematodes. Biol. J. Linn. Soc. 62 : $567-580$.

Poulin, R. (1997b). Population abundance and sex ratio in dioecious helminth parasites. Oecologia (Berl.) 111: 375-380.

Purvis, A., Gittleman, J. L. \& Luh, H.-K. (1994). Truth or consequences: effects of phylogenetic accuracy on two comparative methods. J. theor. Biol. 167: 293-300.

Purvis, A. \& Rambaut, A. (1994). Comparative Analysis by Independent Contrasts (CAIC), version 2.0. Oxford: Oxford University.

Ranta, E., Laurila, A. \& Elmberg, J. (1994). Reinventing the wheel: analysis of sexual dimorphism in body size. Oikos $\mathbf{7 0}$ 313-321.

Richardson, D. J., Martens, J. K. \& Nickol, B. B. (1997). Copulation and sexual congress of Leptorhynchoides thecatus (Acanthocephala). J. Parasitol. 83: 542-543.

Ridley, M. (1983). The explanation of organic diversity: the comparative method and adaptations for mating. Oxford: Clarendon Press.

Shine, R. (1989). Ecological causes for the evolution of sexual dimorphism: a review of the evidence. Q. Rev. Biol. 64: 419-461.

Stearns, S. C. (1992). The evolution of life histories. Oxford: Oxford University Press.

Wedell, N. (1997). Ejaculate size in bushcrickets: the importance of being large. J. Evol. Biol. 10: 315-325.

West Eberhard, M. J. (1983). Sexual selection, social competition, and speciation. Q. Rev. Biol. 58: 155-183.

Wicklund, C. \& Karlsson, B. (1988). Sexual size dimorphism in relation to fecundity in some Swedish satyrid butterflies. Am. Nat. 131: 132-138.

Zar, J. H. (1984). Biostatistical analysis. 2nd edn. Englewood Cliffs, NJ: Prentice-Hall. 
Appendix. Acanthocephalan species used in the analyses and their measurements (all volumes are in $\mathrm{mm}^{3}$ )

\begin{tabular}{|c|c|c|c|c|}
\hline Species & Male volume & Female volume & Testis volume & Female-male size ratio \\
\hline Acanthocephalus alabamensis & 0.323 & 1.097 & 0.030 & 3.393 \\
\hline Acanthocephalus amuriensis & 0.962 & 11.404 & 0.024 & 11.853 \\
\hline Acanthocephalus anguillae & 8.053 & 60.821 & 0.312 & 7.553 \\
\hline Acanthocephalus curtus & 0.222 & 0.519 & 0.010 & 2.335 \\
\hline Acanthocephalus hastae & 3.246 & 8.553 & 0.215 & 2.635 \\
\hline Acanthocephalus japonicus & 3.283 & 9.052 & 0.184 & 2.757 \\
\hline Acanthocephalus lucii & 4.767 & 33.965 & 0.301 & 7.125 \\
\hline Acanthocephalus minor & 1.533 & 2.631 & 0.014 & 1.716 \\
\hline Acanthocephalus nanus & 1.414 & 4.775 & 0.060 & 3.378 \\
\hline Acanthocephalus parksidei & 0.472 & 2.731 & 0.046 & 5.782 \\
\hline Acanthocephalus ranae & 8.310 & 186.533 & 0.117 & 22.448 \\
\hline Acanthocephalus tahlequahensis & 0.608 & 2.730 & 0.020 & 4.493 \\
\hline Acanthocephalus tenuirostris & 1.717 & 1.397 & 0.241 & 0.814 \\
\hline Acanthosentis acanthuri & 12.931 & 16.728 & 0.404 & 1.294 \\
\hline Acanthosentis dattai & 0.200 & 1.962 & 0.035 & 9.803 \\
\hline Acanthosentis sircari & 1.022 & 2.848 & 0.043 & 2.787 \\
\hline Andracantha gravida & 5.110 & 14.082 & 0.063 & 2.756 \\
\hline Andracantha mergi & 4.646 & 15.843 & 0.059 & 3.410 \\
\hline Andracantha phalacorcoracis & 5.267 & 18.357 & 0.036 & 3.486 \\
\hline Atactorhynchus verecundus & 1.272 & 2.026 & 0.023 & 1.592 \\
\hline Australiformis semoni & 197.921 & 790.137 & 2.325 & 3.992 \\
\hline Cavisoma magnum & 28.274 & 123.700 & 0.014 & 4.375 \\
\hline Centrorhynchus amphibius & 4.354 & 23.264 & 0.164 & 5.344 \\
\hline Centrorhynchus crotophagicola & 33.929 & 47.501 & 0.003 & 1.400 \\
\hline Centrorhynchus falconis & 5.195 & 6.650 & 0.056 & 1.280 \\
\hline Centrorhynchus kuntzi & 25.352 & 66.091 & 0.056 & 2.607 \\
\hline Centrorhynchus spilornae & 22.980 & 66.162 & 0.338 & 2.879 \\
\hline Centrorhynchus spinosus & 15.014 & 12.767 & 0.113 & 0.850 \\
\hline Cleaveius circumspinifer & 0.177 & 0.919 & 0.005 & 5.200 \\
\hline Corynosoma bipapillum & 0.832 & 0.832 & 0.016 & 1.000 \\
\hline Echinopardalis atrata & 645.128 & 1565.169 & 5.598 & 2.426 \\
\hline Echinorhynchoides dogieli & 1.481 & 1.798 & 0.119 & 1.214 \\
\hline Echinorhynchus cotti & 3.066 & 5.635 & 0.277 & 1.838 \\
\hline Echinorhynchus gadi & 6.141 & 16.567 & 0.278 & 2.698 \\
\hline Echinorhynchus lageniformis & 1.169 & 0.536 & 0.015 & 0.458 \\
\hline Echinorhynchus lotellae & 3.159 & 24.334 & 0.123 & 7.703 \\
\hline Echinorhynchus parasiluri & 0.283 & 1.696 & 0.045 & 6.000 \\
\hline Echinorhynchus pomatostomi & 127.627 & 97.414 & 0.694 & 0.763 \\
\hline Fessisentis fessus & 9.550 & 33.262 & 0.307 & 3.483 \\
\hline Fessisentis tichiganensis & 1.388 & 2.655 & 0.173 & 1.912 \\
\hline Filisoma indicum & 1.539 & 9.079 & 0.079 & 5.898 \\
\hline Floridosentis elongatus & 14.137 & 19.635 & 0.576 & 1.389 \\
\hline Hemirhadinorhynchus leuciscus & 3.725 & 231.669 & 0.313 & 62.196 \\
\hline Heteracanthocephalus peltorhamphi & 3.920 & 8.791 & 0.244 & 2.243 \\
\hline Heterosentis plotosi & 0.630 & 1.767 & 0.047 & 2.804 \\
\hline Hypoechinorhynchus alaeopis & 1.281 & 4.202 & 0.061 & 3.280 \\
\hline Hypoechinorhynchus thermaceri & 0.557 & 1.045 & 0.015 & 1.878 \\
\hline Leptorhynchoides aphredoderi & 1.162 & 1.951 & 0.055 & 1.679 \\
\hline Leptorhynchoides thecatus & 4.459 & 4.207 & 0.044 & 0.944 \\
\hline Mediorhynchus bakeri & 26.714 & 77.507 & 0.992 & 2.901 \\
\hline Mediorhynchus centurorum & 24.881 & 39.584 & 1.684 & 1.591 \\
\hline Mediorhynchus mattei & 22.808 & 343.612 & 0.524 & 15.065 \\
\hline Mediorhynchus wardi & 10.210 & 54.782 & 0.857 & 5.365 \\
\hline Metechinorhynchus jucundus & 40.841 & 326.726 & 0.487 & 8.000 \\
\hline Metechinorhynchus lageniformis & 1.078 & 10.214 & 0.032 & 9.471 \\
\hline Metechinorhynchus salmonis & 7.367 & 11.009 & 0.133 & 1.495 \\
\hline
\end{tabular}


Appendix (continued)

\begin{tabular}{|c|c|c|c|c|}
\hline Species & Male volume & Female volume & Testis volume & Female-male size ratio \\
\hline Moniliformis acomysi & 26.761 & 46.244 & 0.740 & 1.728 \\
\hline Moniliformis echinosorexi & 219.036 & 670.884 & 6.545 & 3.063 \\
\hline Moniliformis tarsii & 9.647 & 26.609 & 0.246 & 2.758 \\
\hline Neoechinorhynchus coiliae & 2.566 & 25.624 & 0.330 & 9.986 \\
\hline Neoechinorhynchus constrictus & 9.651 & 12.146 & 0.175 & 1.259 \\
\hline Neoechinorhynchus crassus & 1.307 & 3.313 & 0.067 & 2.536 \\
\hline Neoechinorhynchus cristatus & 0.452 & 1.712 & 0.039 & 3.786 \\
\hline Neoechinorhynchus cylindratus & 1.058 & 0.926 & 0.023 & 0.875 \\
\hline Neoechinorhynchus formosans & 19.000 & 25.635 & 0.933 & 1.349 \\
\hline Neoechinorhynchus limi & 0.318 & 0.416 & 0.016 & 1.306 \\
\hline Neoechinorhynchus lingulatus & 17.495 & 28.230 & 0.225 & 1.614 \\
\hline Neoechinorhynchus robertbaueri & 0.459 & 2.468 & 0.040 & 5.379 \\
\hline Neoechinorhynchus rutili & 0.889 & 2.115 & 0.072 & 2.379 \\
\hline Neoechinorhynchus salmonis & 2.815 & 6.833 & 0.205 & 2.427 \\
\hline Neoechinorhynchus stunkardi & 15.580 & 24.715 & 0.259 & 1.586 \\
\hline Neoechinorhynchus topseyi & 4.793 & 29.845 & 0.046 & 6.226 \\
\hline Neoechinorhynchus tumidus & 4.585 & 23.103 & 0.263 & 5.038 \\
\hline Neoechinorhynchus tylosuri & 30.122 & 57.638 & 0.836 & 1.913 \\
\hline Neoncicola sinensis & 23.115 & 78.540 & 0.219 & 3.398 \\
\hline Octospiniferoides chandleri & 0.055 & 0.329 & 0.005 & 5.994 \\
\hline Oncicola martini & 37.883 & 43.277 & 0.858 & 1.142 \\
\hline Oncicola schacheri & 433.541 & 660.031 & 5.698 & 1.522 \\
\hline Owilfordia olseni & 88.737 & 184.294 & 0.006 & 2.077 \\
\hline Pararhadinorhynchus aspinosus & 11.140 & 14.440 & 0.237 & 1.296 \\
\hline Paratenuisentis ambiguus & 1.916 & 6.626 & 0.219 & 3.458 \\
\hline Paulisentis fractus & 0.714 & 1.422 & 0.041 & 1.992 \\
\hline Pilum pilum & 2.295 & 8.406 & 0.132 & 3.662 \\
\hline Plagiorhynchus bullocki & 14.250 & 52.916 & 0.006 & 3.713 \\
\hline Plagiorhynchus charadrii & 9.348 & 12.579 & 0.154 & 1.346 \\
\hline Plagiorhynchus taiwanensis & 48.707 & 86.124 & 0.012 & 1.768 \\
\hline Polyacanthorhynchus macrorhynchus & 165.484 & 2721.411 & 8.294 & 16.445 \\
\hline Polymorphus formosus & 112.595 & 234.346 & 1.111 & 2.081 \\
\hline Polymorphus petrochenkoi & 19.113 & 41.695 & 0.350 & 2.181 \\
\hline Pomphorhynchus laevis & 22.706 & 174.948 & 0.631 & 7.705 \\
\hline Pomphorhynchus lucyi & 4.398 & 4.477 & 0.047 & 1.018 \\
\hline Pomphorhynchus rocci & 10.210 & 17.255 & 0.388 & 1.690 \\
\hline Pomphorhynchus sebastichthydis & 11.045 & 19.813 & 0.296 & 1.794 \\
\hline Pomphorhynchus yamagutii & 2.395 & 5.445 & 0.044 & 2.274 \\
\hline Porrorchis elongatus & 87.793 & 178.924 & 0.005 & 2.038 \\
\hline Porrorchis hylae & 30.680 & 103.276 & 0.383 & 3.366 \\
\hline Porrorchis leibyi & 59.266 & 109.051 & 0.665 & 1.840 \\
\hline Prosthorhynchus formosus & 32.987 & 58.905 & 0.0002 & 1.786 \\
\hline Pseudolueheia pittae & 49.880 & 71.676 & 0.005 & 1.437 \\
\hline Pseudorhadinorhynchus neobythitis & 1.649 & 3.777 & 0.087 & 2.291 \\
\hline Quadrigyrus nickoli & 3.054 & 8.808 & 0.151 & 2.884 \\
\hline Rhadinorhynchoides mijagawai & 8.482 & 20.358 & 0.116 & 2.400 \\
\hline Rhadinorhynchus cololabis & 7.383 & 27.428 & 0.258 & 3.715 \\
\hline Rhadinorhynchus ditrematis & 4.719 & 11.473 & 0.149 & 2.431 \\
\hline Rhadinorhynchus ornatus & 2.887 & 3.958 & 0.030 & 1.371 \\
\hline Rhadinorhynchus pristis & 1.833 & 1.308 & 0.036 & 0.714 \\
\hline Rhadinorhynchus trachuri & 2.121 & 2.827 & 0.117 & 1.333 \\
\hline Sachalinorhynchus skrjabini & 2.162 & 7.313 & 0.058 & 3.383 \\
\hline Sclericollum rubrimaris & 25.002 & 32.974 & 0.403 & 1.319 \\
\hline Southwellina dimorpha & 14.137 & 29.568 & 0.094 & 2.092 \\
\hline Sphaerechinorhynchus serpenticola & 30.042 & 49.308 & 0.473 & 1.641 \\
\hline Sphaerirostris wertheimae & 55.469 & 103.346 & 0.477 & 1.863 \\
\hline
\end{tabular}

